\title{
New evidence about the use of serpentinite in the Minoan architecture. A $\mu$-Raman based study of the "House of the High Priest" drain in Knossos
}

\author{
Ioannis Grammatikakis,,${ }^{\mathrm{a}, \mathrm{c}}$ Konstantinos D. Demadis, ${ }^{\mathrm{a}}$ Evangelos Kyriakidis, ${ }^{\mathrm{b}, \mathrm{c}}$
} Aurelio Cabeza, ${ }^{\mathrm{d}}$ Laura Leon-Reina ${ }^{\mathrm{e}}$

a) Crystal Engineering Growth and Design Laboratory, Department of Chemistry, University of Crete, 71003-Voutes Campus Heraklion, Crete Greece

b) Classical and Archaeological Studies, School of European Culture and Languages, University of Kent, Canterbury, Kent, CT2 7N, United Kingdom.

c) Initiative for Heritage Conservation, Kimonos 11 and Pangalou 19200-Elefsina, Greece

d) Departamento de Química Inorgánica, Cristalografía y Mineralogía, Universidad de Málaga, 29071-Málaga, Spain

e) Servicios Centrales de Apoyo a la Investigación, Universidad de Málaga, 29071-Málaga, Spain

\begin{abstract}
Serpentinites have been widely used as a raw material in a huge repertoire of shapes during the Minoan period, for the construction of artefacts both for domestic use as well as for religious purposes. However, the utilization of serpentinites is extremely limited in the Minoan palatial architecture. In all the cases where the use of serpentinite is documented, it has been for the construction of column bases. The aim of this study is the investigation of the material used for the construction of the drain located under the stair leading to the adyton (sanctuary) of the "House of the High Priest" one of the peripheral monuments of the Palace of Knossos.

Despite the fact that Sir A. Evans documented the stone drain and described the raw material as stone, no further comments were made regarding the exact type of stone used by the Minoans. Furthermore, the fact that a rather unusual material was used for the construction of a drain instead of a more typical material such as limestone or sandstone, enhances the illdefined and controversial character of the "House of the High Priest".

The initial mineralogical characterization of the drain material was carried out by means of $X$ ray powder Diffraction leading to the identification of several minerals and polymorphs. Further examination of the sample in terms of microstructural and chemical analysis of the different inclusions was implemented by means of confocal $\mu$-Raman spectroscopy. Within the concept of this study emphasis is given to the application of this nondestructive and noninvasive technique that can be applied in situ for the analysis and characterization of objects of archaeological significance made out of serpentinite minerals, where often sample acquisition is not possible.

The choice of Raman spectroscopy as the main non-destructive analytical tool consists a strategic decision for two main reasons: (a) There are several other architectural elements implemented in the Minoan palatial architecture allegedly made out of serpentinite that macroscopically bear different characteristics and have to be examined, and (b) the majority of the Minoan stone vases corpus is consisted of artifacts made out of serpentinite but in both
\end{abstract}


cases sampling is not possible. Lastly, the correlation of the data acquired from the analysis of the serpentinite outcrops on the island of Crete, with those from the archaeological objects might augment the development of knowledge regarding the cultural networks among the agricultural areas, where the serpentinite sources are located towards the centers of the Minoan civilization.

\section{Introduction}

Serpentinites have been used since antiquity as raw materials for the construction of objects for both domestic use as well as for religious purposes (Rapp, 2002). One of the earliest pieces of evidence is the example of the three toads carved in serpentinite that were excavated, at the $7^{\text {th }}$ millennium BCE settlement of Nea Nicomedia, Greece. Those sculptures were also considered as the earliest samples of decorative artifacts of the earliest Neolithic era (Rodden, 1962). The use of this material is also documented in the Mesopotamia. One of the most characteristic Mesopotamian examples is the sculpture of a human headed bison, dated to the Second Dynasty of Lagash, ca. 2100 BCE (Rodden, 1962). Serpentinites was also used for vases and ceremonial heads in ancient Egypt (Rapp, 2002).

Vases carved of serpentinite were also found at Minoan Crete. Cretan artisans made use of ophiolithic rocks, among which serpentinites, in a huge repertory of shapes. Stone vases, jars, ladles, lamps, amphorae, offering tables, goblets, rhytons and bowls were excavated from areas with Minoan presence as well as from the palatial complexes (Warren, 1993, Hatzaki, 2005, Mountjoy et. al., 2003). In Knossos, Phaestos, Zakros, Palaikastron, Aghia Triada (Crete, Greece), many objects carved in serpentinite have been also discovered (Shaw, 2009, Hatzaki 2005). According to Warren (1969), almost half of the entire corpus of the Minoan stone vases is consisted of objects made out of serpentinite. However, the utilization of serpentinites for building purposes is limited in Minoan palatial architecture.

Several cases of column bases made of some kind of serpentinite aggregated with other minerals, engendering polychromy have been documented (Evans, 1921, 1928, Shaw, 1973). The aforementioned architectural elements can be found in almost all the centers of the Minoan civilization i.e. in Knossos, Phaistos, Hagia Triada, Kato Zakros, but in limited quantities or partially preserved. This is due to the fact that the aesthetic value of the polychrome serpentinites aggregated with other minerals were valued by the Minoans during the early phases of their civilization (Evans, 1921, 1928). Nevertheless, it is beyond any doubt that serpentinite was a material greatly valued during the Minoan period.

In this paper based on the mineralogical analyses described in detail below we report that the raw material used for the construction of the "House of the High Priest" drain is characterized as serpentinite. Serpentinite is a rock. Serpentine is a mineral or more precisely mineral group. Serpentinite is composed of serpentine. Serpentinites are part of the ophiolitic mélange. These contain large blocks of serpentinized ultramafic rocks, actinolite-fuchsite alterations of smaller ultramafic blocks, altered gabbro, a variety of clastic sedimentary blocks, and marble Lizardite, chrysotile and antigorite represent one of the most fascinating, yet not fully understood, case of polymorphism. They are hydrous phyllosilicate minerals belonging to the group of serpentines, and have an ideal formula unit corresponding to $\mathrm{Mg}_{3} \mathrm{Si}_{2} \mathrm{O}_{5}(\mathrm{OH})_{4}$. While lizardite has been characterized with a high level of the other two polymorphs are still a matter 
of study, together with the reasons that cause such a diverse range of structures (Demichelis et. al., 2016). Due to this fact the term pseudo - polymorphs will be used.

This fact is in contradiction to what is considered as typical given that always where the presence of stone drains is certified, those architectural elements are carved in other types of rock such as limestone or sandstone as well as in different shapes i.e.: semicircular, built sides, covered (Evans, PM I, II, III, Shaw, 1973). The new evidence regarding the characterization of the ancient drain material is of great significance since the use of a material with rather peculiar properties is confirmed. A material that is widely utilized for the construction of artifacts, but its use for architectural purposes, is extremely limited during the neopalatial period. Hence, the serpentinite drain located in the "House of the High Priest", can be characterized as a unique case.

Furthermore, it is demonstrated that through the use of $\mu$-Raman spectroscopy, a nondestructive, non-invasive technique that can be applied on site, it is possible to distinguish between the serpentine minerals. This information can be of crucial importance for a complete and in depth study as well as for the preliminary provenance of serpentinites within the context of the Minoan civilization.

\section{Archaeological evidence}

In the winter period of 2012-2013, during restoration applications on the "House of the High Priest" (project: "Conservation and restoration of the peripheral monuments of the archaeological site of Knossos") a part of an ancient stone drain came to light (Figure 1).

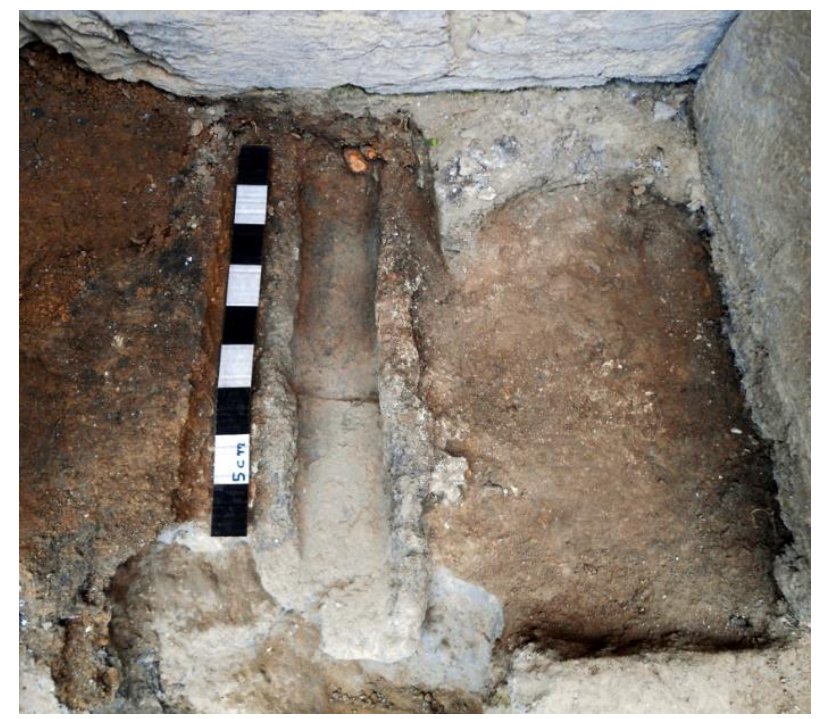

Figure 1. The part of the ancient drain exposed during the restoration works

The partially preserved monument is located south of the Palace of Knossos, within a distance of 400 meters, between the "Caravanserai" and "Temple Tomb". It was discovered in 1931 by Sir A. Evans, who also implemented its restoration. According to the excavator, the "House of the High Priest" dates from the late MM III period but was in use until LMIII (Driessen, 1990). A balustrade supporting two columns separates the fore-hall from the inner part of the 'private Chapel' of the "House of the High Priest". A stepped passage in the center of the balustrade leads westwards to the inner 'chancel (ádutov, adyton)'. This architectural form constitutes a unique architectural feature that occurs only at Knossos. On the restored floor of the 'adyton' the position of a circular hole indicates the existence of a drain that went under 
the stepped access to the forehall. A small part of this drain is visible today at the eastern end of the first step (Grammatikakis \& Anagnostaki, 2013).

The flow of the water over the steps of the scale, carved in selenite (mineral gypsum), leading to the adyton, apart from the degradation of the selenite surfaces, eventually resulted to the loss of cohesion of the soil, supporting the steps. Therefore the removal of the first step was considered as a first priority, primarily in order to create a coherent substrate for the step to be restored to its original position. The removal of the aforementioned architectural element, brought to light a part of the ancient drain. The direction of the drain as well as the potential inflow hole, were described in the design of the monument by the architect Piet de Jong (Evans, PM IV). According to the excavator, this drain which was used to effuse the blood of the animal sacrifices in the 'adyton' (Evans PM IV), was made out of stone, nevertheless Evans does not make any comments about the type of stone used as a raw material.

According to Gesell, the drain could be used for liquid offerings (Gesell, 1985) while according to MacDonald and Driessen (Driessen and MacDonald, 1997) the main function of drains is always the same, the runoff of liquids, originating either from domestic or from religious activities. The small part of the drain uncovered, has a maximum visible length of 0.55 meters and width of 0.095 meters. The internal surface is U-shaped, while in the middle of its length there is a transverse fissure. The preserved height of the drain walls are ranged between 0.02 meters to 0.065 meters with an average thickness of 0.045 meters. The part of the drain uncovered are not very well preserved due to mechanical stress because of the extensive growth of roots (Grammatikakis \& Anagnostaki, 2013).

\section{Experimental}

A small sample of approximate size of $1 \mathrm{~cm}^{3}$ has been acquired from the disintegrated material of the ancient drain, under the permission of the Ephorate of Antiquities of Heraklion (Crete, Greece). A petrographic analysis was not carried out due to the limited availability of the original material, hence the preparation of thin sections was impossible.

The preliminary identification of the raw material of the ancient drain, was implemented by X-Ray powder diffraction (XRPD). The XRPD pattern was collected using a PANalytical X'Pert Pro automated diffractometer equipped with a Ge (111) primary monochromator ( $\mathrm{Cu} \mathrm{Ka} 1$ ) and the $X^{\prime}$ Celerator detector with a step size of $0.017^{\circ}(2 \theta)$. The powder pattern was recorded between 2 and $80^{\circ}$ in $2 \theta$ with a total measuring time of at least $30 \mathrm{~min}$.

In order to fulfill clay mineral identification flow diagram (U. S. Geological Survey Open-File Report 01-041, https://pubs.usgs.gov/of/2001/of01-041/htmldocs/flow/) the diffraction patterns were recorded in the randomly oriented powder sample and in oriented aggregates: i) air dried aggregate, ii) treated with ethylene glycol and iii) heated at $550^{\circ} \mathrm{C}$ during $30 \mathrm{~min}$. Phase identification was performed with X'Pert HighScore Plus v.2.0e software using the PDF database. Identification could lightly differ from microcopy studies due to the specific micro morphology of the samples.

Following the mineralogical analysis and characterization of the mineral constituents of the material of the ancient drain through XRPD, the remaining sample was polished in order to be examined under a confocal Raman microscope. The Raman spectra were recorded on a Thermo Scientific Nicolet Almega XR Dispersive Raman Spectrometer confocal with an Olympus BX43 microscope with a long distance 50x objective lens and an excitation laser with $\lambda=780 \mathrm{~nm}$, at $40 \mathrm{~mW}$, operating at high resolution. The spectral range was between $100-$ 
$3100 \mathrm{~cm}^{-1}$ and the acquisition time was 100 seconds. The standard calibration process as proposed by the manufacturer company (Thermo Scientific) was applied by the laboratory stuff, using the $520.7 \mathrm{~cm}^{-1}$ peak of silicon as a standard.

\section{Results}

\section{Mineralogical analysis and preliminary study of the material of the ancient drain}

Rocks are consisted of minerals, usually more than one. Consequently, the summary of the characteristic reflection angles for each mineral, is presented in a $2 \theta \mathrm{X}$-Ray diffraction diagram, which represents the virtual fingerprint for the family of minerals under study. The categorization of the rock that was used as a raw material for the construction of the "House of the High Priest" drain, as a serpentinite, was based on the presence of the characteristic diffraction angles of monoclinic pseudo-polymorphs of serpentine groups: chrysotile, lizardite and antogorite (Whittaker \& Zussman, 1956, Wicks \& Whittaker, 1975). Chrysotile usually shows a fibrous habit meanwhile the other two pseudo-polymorphs have a platy habit.

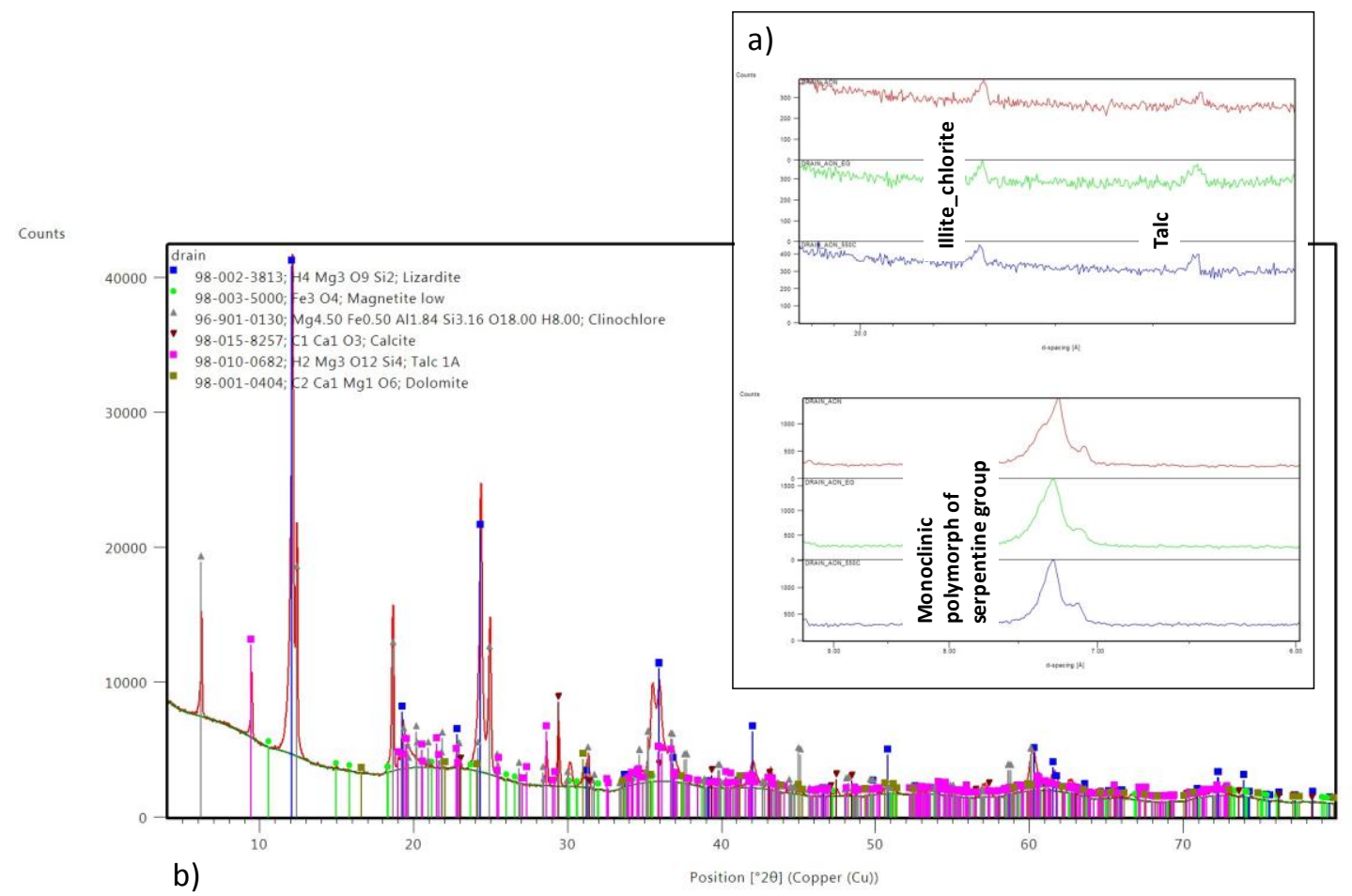

Figure 2. The powder X-Ray diffraction pattern of the sample from the ancient drain: (a) orientated aggregates and heated sample; (b) phase identification.

The behavior of the oriented aggregates with ethylene glycol and temperature clearly indicate the presence of interstratified minerals of illite-chrolite and talc groups in addition to the characteristic diffraction peaks of serpentine minerals (Figure 2a). The mineral phase identification by XRPD is shown in Figure $2 b$. The comparison of the pattern with the PDF database allows the total identification of the reflections with the following minerals: serpentine (one of the three monoclinic pseudo-polymorphs, lizardite, antigorite or chrysotile), magnetite, chlorite (clinochlore), calcite, talc and dolomite.

Following the initial mineral phase identification through powder XRD, a thorough examination of the sample from the drain was carried out by means of micro Raman 
spectroscopy in order to identify which polymorph of the serpentine family is present. Through this approach is was made possible to examine specific areas (inclusions), correlating the crystallographic and chemical information with the micromorphology of the rock sample.

In this study several Raman spectra were acquired from the sample of the ancient drain. In the Raman spectra shown in Figure 3, the presence of chrysotile, calcite and steatite is documented. In Spectrum 1 the two Raman spectra the presence of chrysotile is indicated by the presence of the Raman bands at 232, 348, 391, $622 \mathrm{k \alpha l} 690 \mathrm{~cm}^{-1}$.
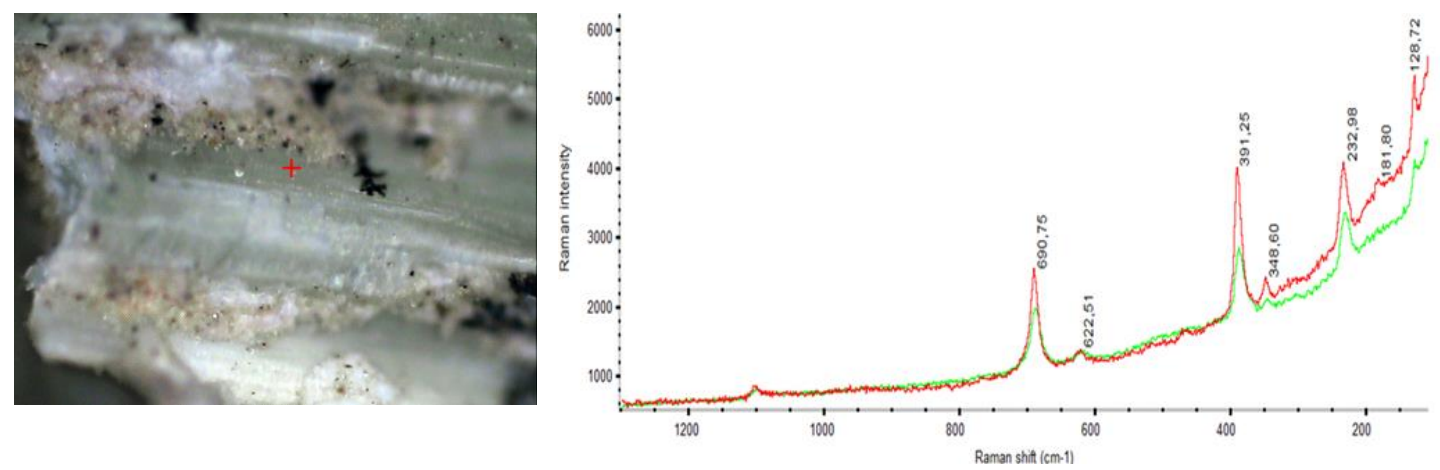

Figure 3. Two Raman spectra of chrysotile obtained for two different spots from the sample of the High Priests House drain near Knossos.

For band assignment of the serpentinite spectra, the work of Rinaudo et al. (2003) has been used (Rinaudo et al., 2003). Consequently, the spectra are characterized by the following main bands of chrysotile assigned according to the description of the vibrational bands in the IR spectra of the phyllosilicates proposed by Lazarev (Lazarev, 1972) and Farmer (Farmer, 1974) and to the assignment for Raman bands in tubular chrysotile, as suggested by Kloprogge (Kloprogge et al., 1999). The intense band at $690 \mathrm{~cm}^{-1}$, is attributed to the symmetric stretching mode $\left(\mathrm{V}_{\text {as }}\right)$ of the $\mathrm{Si}-\mathrm{O}_{\mathrm{b}}-\mathrm{Si}$ groups.

The Raman peaks in the spectral region $800-600 \mathrm{~cm}^{-1}$ are contributed by the vibrational modes of $\mathrm{Si}-\mathrm{O}_{b}-\mathrm{Si}$ bonds $\left(\mathrm{O}_{\mathrm{b}}=\right.$ bridging oxygen), which connect the $\mathrm{SiO}_{4}$ tetrahedra that make up a layer. Most tri-octahedral phyllosilicates show a strong peak in the range $700-670 \mathrm{~cm}^{-1}$. The equivalent $\mathrm{Si}-\mathrm{O}_{b}$-Si peak of di-octahedral phyllosilicates normally occurs above $700 \mathrm{~cm}^{-1}$ except for Fe-rich nontronite. The strong intensity of the band at $690 \mathrm{~cm}^{-1}$ and the presence of the band at $391 \mathrm{~cm}^{-1}$ may be related to the presence of chrysotile, in which the vs modes of the $\mathrm{Si}-\mathrm{O}_{\mathrm{b}}-\mathrm{Si}$ linkages lie at $692 \mathrm{~cm}^{-1}$ and the vs(e) vibrational modes of the $\mathrm{TO}_{4}$ tetrahedra are found at $389 \mathrm{~cm}^{-1}$ (Rinaudo et al. 2003).

The band at $620 \mathrm{~cm}^{-1}$ produced, following Kloprogge (Kloprogge et al., 1999) , by OH-Mg-OH translation modes on the basis of the assignment of the band at $627 \mathrm{~cm}^{-1}$ observed on the infrared spectrum of brucite $\left(\mathrm{Mg}(\mathrm{OH})_{2}\right)$. The Raman bands in spectral region $1150-800 \mathrm{~cm}^{-1}$ arise from the stretching mode of the $\mathrm{Si}-\mathrm{On}_{b}$ bond $\left(\mathrm{On}_{b}=\right.$ non-bridging oxygen) in $\mathrm{SiO}_{4}$ tetrahedra. Most trioctahedral phyllosilicates have one or more medium-strength and welldistinguished Raman peak(s) in this region, whereas similar peaks from di-octahedral phyllosilicates are weaker and spread across a wider region. This difference can be assigned to effects of the higher electronegativity of $\mathrm{Al}^{3+}$ and higher covalency of the Al-On $\mathrm{n}_{\mathrm{b}}$ bond, thus causing a lower fraction NBO $<1$ (NBO = number of non-bridging oxygens) in di-octahedral compared with NBO = 1 in tri-octahedral phyllosilicates [Wang et al., 2002). The two bands at 390 and $348 \mathrm{~cm}^{-1}$, appear in the spectral region where the bending vibrations of the $\mathrm{SiO}_{4}$ 
tetrahedra are observed. The first one was assigned by Kloprogge (Kloprogge et al., 1999) to the vs(e) bending modes of the $\mathrm{SiO}_{4}$ tetrahedra. The band observed at $232 \mathrm{~cm}^{-1}$ in the spectral region where vibrations of the $\mathrm{O}-\mathrm{H}-\mathrm{O}$ groups are expected (Griffith 1969, Loh, 1973). Although the strong vibrational bands at 391 and $690 \mathrm{~cm}^{-1}$, characteristic of both chrysotile and lizardite, are present, the weak band at $622 \mathrm{~cm}^{-1}$ is characteristic of chrysotile only. This is in agreement with the X-ray powder diffraction data (Figure 2).

In Figure 4, the characteristic Raman bands of steatite are observed at 194, 292, 360, 432, 466 and $676 \mathrm{~cm}^{-1}$. The strong vibrational band that appears at $676 \mathrm{~cm}^{-1}$ is assigned to the symmetric bending vibration of $\mathrm{Si}-\mathrm{O}_{b}-\mathrm{Si}$ bridges in the silicate chains and is characteristic of protoenstatite, one of the three polymorphs of steatite (Reynard et al., 2008)
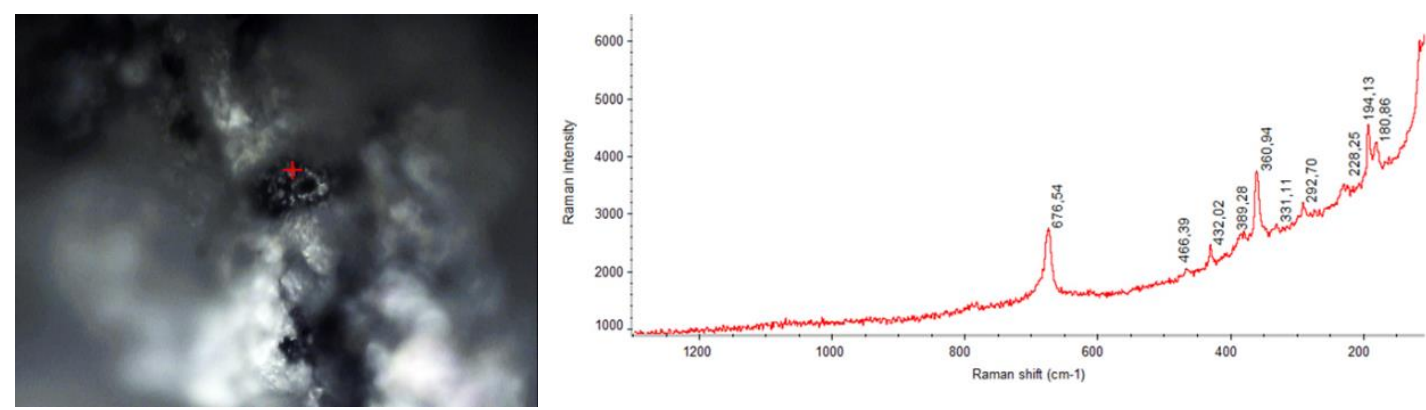

Figure 4. The characteristic Raman bands of steatite, obtained from the ancient drain sample.
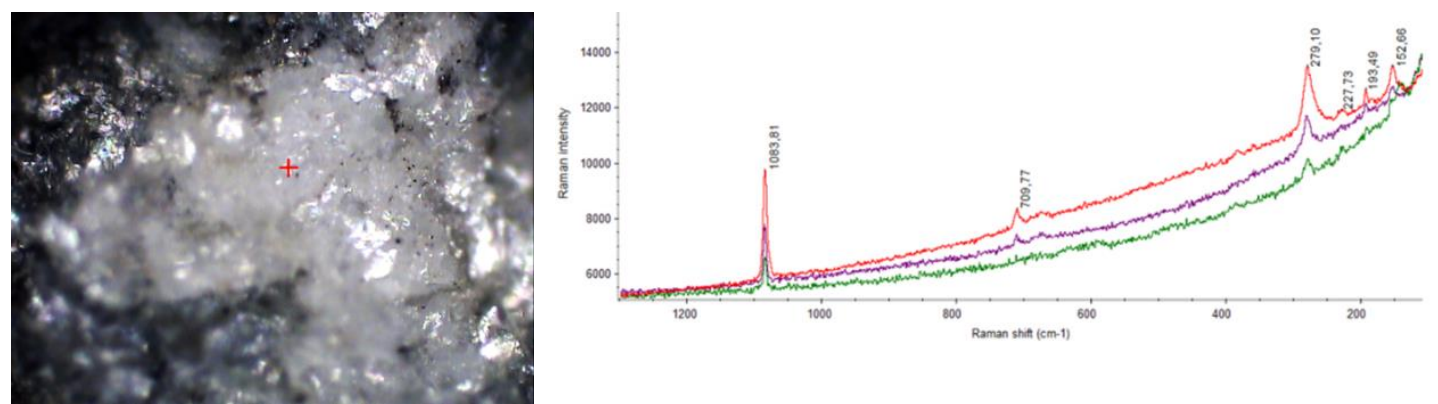

Figure 5. Presence of calcium carbonate as identified in the sample of the ancient drain by Raman spectroscopy. Spectra obtained from different spots of the sample.

In Figure 5, the presence of calcium carbonate is demonstrated through the characteristic Raman bands at 156, 280, $710 \mathrm{k \alpha} 1087 \mathrm{~cm}^{-1}$. The most intense Raman band observed at 1085 $\mathrm{cm}^{-1}$ is assigned to the symmetric stretching vibration of the carbonate anion $\left(\mathrm{CO}_{3}{ }^{2-}\right)$, however, it is common for all three polymorphs of this compound, ie. calcite, aragonite and vaterite. The unequivocal presence of calcite was confirmed by the XRPD analysis. Based on this observation, the rock used as raw material for the construction of the drain in the "House of the High Priest", can be characterized as ophicalcite.

Serpentinites possess different crystal structures and demonstrate different crystal habits. This property as well as the fact that Cretan serpentinite outcrops present some specific peculiarities as regards to the serpentine pseudo-polymorphs distribution, is a very important indication in the context of a provenance approach of "House of the High Priest" drain raw material. 


\section{Discussion}

The outcome of a thorough survey of the archaeological and the geological literature was that most Cretan serpentinite outcrops are located in the central and south parts of the Heraklion and Lasithi prefectures as well as at the Spili region in central Rethymon (Koepke 2002, Tortorici 2012). In most of those areas, several Minoan settlements can be found, besides the serpentinite outcrops (Warren 1969), see Figure 6.
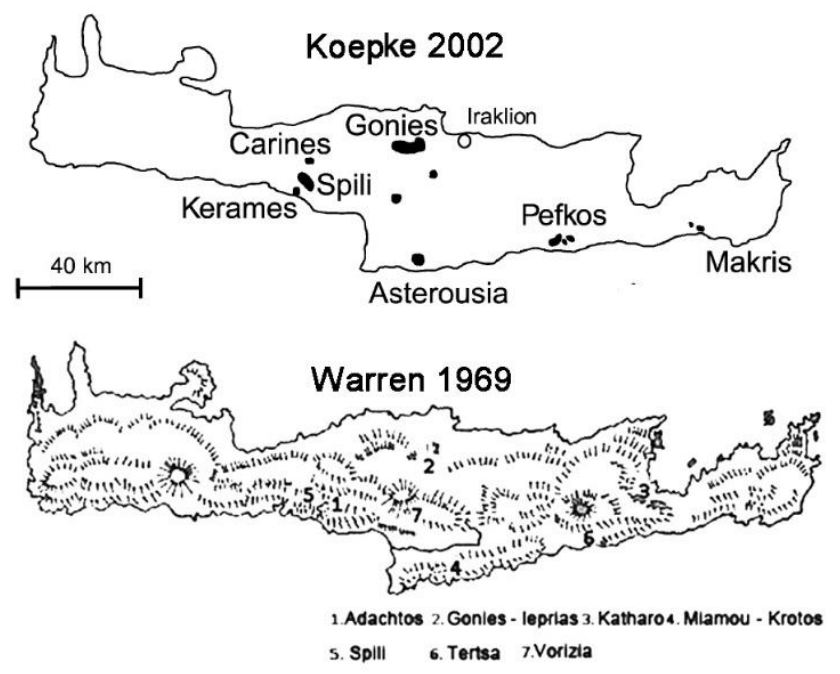

Figure 6. The serpentinite outcrops of Crete after Koepke et al. (2002) and Warren (1969).

The most important evidence with regards to the serpentinite outcrops distribution in Crete and the pseudo-polymorphs present in each location, is the fact that the variety of serpentinites found in the Asterousia region consists entirely of antigorite (Koepke et al. 2002).

Consequently, the exclusion of all locations from the Asterousia region as possible origins of the ancient drain raw material could be suggested. Based on the archaeological and geological literature related to the serpentinite outcrops on the island of Crete, the remaining locations are the Philioremos outcrop, in the village of Gonies $(\sim 20 \mathrm{~km})$ and the areas of Spili and Ardachtos ( $60 \mathrm{~km}$ ), west of Heraklion. Gonies, together with the area of Spili, are regarded the two largest sources of serpentinite in Crete, with Gonies being the closest to Knossos region.

It has to be stressed out that the serpentinite outcrops of Philioremos-Gonies, is part of the greater ophiolitic complex of Anogia which extends to an area of approximately $14 \mathrm{~km}^{2}$ and consists the largest ophiolitic outcrop on the island of Crete (Thorbecke, 1972, Orphanoudaki - Manousaki, 1987). Those rock formations consisting mostly of serpentinites and pyroxenes make up the entire hill of Philioremos. From a mineralogical point of view the serpentinites located in Gonies as well as in Spili, are consisted of all three pseudo-polymorphs: chrysotile, lizardite and antigorite (Koepke, 2002). Nevertheless in the specimens analyzed no antigorite was identified.

It has been reported that the provenance of the serpentinite variety of the Knossos lapidaries can be connected to the outcrops located in the Philioremos-Gonies area (Warren, 1965). Evidence for its procurement were identified in both beds of a ravine called Leprias. Warren also identified on the top of the ravine, near the foothills of Philiorimos, an extensive Middle 
Minoan I-Late Minoan I settlement, below the MMII-MMIII Minoan Peak Sanctuary, while several other sites and surface finds are recorded on the opposite side, near the village of Sisarcha (Athanasaki, 2014).

As regards to the use of this material for the construction of an architectural element with specific use, serpentinites are rather difficult to carve and cannot cut with a saw as easy as other types of stones. On the other hand, serpentinites are materials tolerant to temperature fluctuations that have been used for the construction of offering tables, special vases as well as moulds for jewelry.

Morover, it has been demonstrated that the minerals of the serpentine family are only stable in alkaline media (Spiel \& Leineweber, 1969, Choi \& Smith, 1972). Leaching experiments have shown that the $\mathrm{Mg}$ is readily leached out of the silicate structure once the fibers are exposed to acidic conditions (Clark \& Holt, 1960, Monkmann, 1971, Morgan et al. 1971, Morgan and Holmes 1986). It has also been suggested that smectite is the main weathering product of the serpentinite material (Schreier et al., 1987). The absence of this mineral is a possible indication regarding the use of the drain as it makes it possible for neutral and alkaline liquids to be flushed in very high or very low temperatures yet acidic liquids such as wine, sour milk or many other fermented drinks would have damaged the drain.

\section{Conclusions}

In many cases the morphological values of an archaeological object consist of the most important aspects that have to be preserved. In such cases, extensive and systematic sampling, or even the acquisition of a small fragment are out of the question. It has been demonstrated here, as well as in many relevant papers, that Raman spectroscopy can provide valid information that can be used for the characterization of minerals. Nevertheless, although the sole application of Raman spectroscopy can assist towards the characterization of a mineral, it is not enough when stoichiometric (quantitative and qualitative) information is needed.

New evidence have been provided as regards to the raw material of a peculiar architectural element located in the "House of the High Priest" one of the palatial monuments of Knossos. Although the excavator identifies the material of the drain as stone, no comments regarding the type of stone were available. It has been demonstrated that the stone used for the construction of a drain, with ritual use according to Sir A. Evans, belongs to the family of ophiolites since the dominant minerals are chrysotile and lizardite, two out of the three pseudo-polymorphs of the serpentine family of minerals.

Within the context of this study, it is of minor importance whether the 'adyton' of the "House of the High Priest" is a sacred site or not, since the use of serpentinites for the construction of architectural elements, is particularly out of the ordinary in the neopalatial period. In previous periods serpentinite containing rocks were used due to their aesthetic values (PM I.II, 213). Nevertheless in the case of the "House of the High Priest", the fact that the drain was "hidden" increases the chances that this material was used because of its properties (imaginary or real) and not for its appearance.

Based on the results of this study there are indications that the outcrops located in the south areas of Heraklion and Lasithi could be excluded as possible areas of origin. According to P. Warren: "Extensive deposits, indistinguishable in appearance from those used for vases, occur on both sides of a narrow valley called Lepria, at a spot immediately south of the road about 
$2.3 \mathrm{~km}$ west of Gonies in the northern foothills of Mt. Ida." makes that route in upland Malevyzi from Anogeia to Knossos, via Kylistos and Gonies, a very important one for a most interesting material of Minoan craftsmanship (Warren, 1969). In terms of cultural and trading networks, Warren also mentions that "there would have been an accessible route for getting the material to Knossos, down the Gonies valley past the Minoan villa of Sklavokampos (LM I), on to Tylissos and then down to the coastal plain and Knossos." The possible provenance of serpentinites from below the Philioremos peak sanctuary makes that route in upland Malevyzi from Anogeia to Knossos, via Kylistos and Gonies, highly significant, for one of the most important materials used for Minoan crafts. It represents one of the few instances where a trade route within Crete has been discovered based on the provenance of a particular type of stone used as a raw material.

All the above consolidate a working hypothesis. Nevertheless further sampling and analysis is necessary in order to be able to acquire more precise data about the composition of the serpentinite outcrops in Crete. In the same context, the rest of the Minoan serpentinitic architectural elements will be analyzed. For this purpose Raman spectroscopy is considered to be a useful nondestructive and noninvasive analytical tool that can be applied in situ, providing reliable data for distinction of the three common phases of serpentine minerals.

\section{Acknowledgements}

We thank the Heraklion Ephorate of Antiquities, Hellenic Ministry of Culture and Sports and the European Union's Framework Programme for Research and Innovation HORIZON 2020 for funding the project HERACLES under grant agreement No 700395. 


\section{References \\ K. Athanasaki}

A Serpentine Quarry-Scape in Gonies, North-Central Crete

PHYSIS, AEGAEUM 37 (2014), pp. 67-72

I. Choi, R. W. Smith

Kinetic study of dissolution of asbestos fibers in water

Colloid Interface Sci. 40 (1972), pp. $253-262$

S.G. Clark, P.F. Holt

Dissolution of chrysotile asbestos in water, acid and alkali

Nature 185 (1972), p. 237

R. Demichelis, M. De La Pierre, M. Mookherjee,b C. M. Zicovich-

Wilsonc and R. Orlandod

Serpentine polymorphism: a quantitative insight from first-principle calculations

CrystEngComm, 2016, 18, 4412-4419

J. Driessen

An early destruction in the Mycenaean Palace at Knossos: A new interpretation of the excavation field notes of the south-east area of the west wing

Leuven: Katholeke Universitet leuven (1990), pp.121, ftn.424

J. Driessen, and C.F. MacDonald

A Gazetteer of Neopalatial Sites on Crete and the Southern Aegean Islands Aegaeum 17, Liège (1997), pp. 119-258

A. Evans

The Palace of Minos at Knossos

I, II, III, IV, New York, (1964), pp. I, 141-3, 213, 225-30, 327, 334-5, 363, 378-80, 393-6, 400,

II, 161, III, 5, 236-44, 245-59, 492

R.D.G. Evely

Minoan Crafts: Tools and Techniques. An Introduction

SIMA V.XCII, Göteborg, (1993), pp. 156-7., 172, 150, 162, 156-7

V.C. Farmer

The Infrared Spectra of Minerals

The Mineralogical Society, London, U.K. (1974)

G. C. Gesell

Town, Palace, and House Cult in Minoan Crete

SIMA L.XVII, Göteborg, (1985), p.21.

I. Grammatikakis, G. Anagnostaki

Restoration and preservation project of architectural elements of gypsum in the "High Priest's House", a peripheral monument of the Palace of Knossos, from the eroding action of the rain water and the investigation of the excavated duct

3rd Meeting for the Archaeological Work in Crete, Rethymno Crete 5-8 December 2013 
W.P. Griffith

Raman studies on rock-forming minerals. I. orthosilicates and cyclosilicates

J. Chem. Soc. (A) 9 (1969), pp. 1372-1377

P.O. Harper

Human headed bison

Metropolitan Mus. Art Bull 55(2):8, (1997)

E. Hatzaki

Knossos. The Little Palace

BSA Suppl. Vol., no. 38. (2005), pp. 185, 124, 185

J. T. Kloprogge, R. L. Frost, L. Rintoul

Single crystal Raman microscopic study of the asbestos mineral chrysotile

Phys. Chem. Chem. Phys., Vol. 1 (1999) pp. 2559 - 2564

J. Koepke, S. Eberhard, H. Kreuzer

Ophiolites on the Southern Aegean islands Crete, Karpathos and Rhodes: composition, geochronology and position within the ophiolite belts of the Eastern Mediterranean Lithos 65 (2002), p. 193

A.N. Lazarev

Vibrational Spectra and Structure of Silicates

Consultant Bureau, New York, N.Y. (1972)

M. Lemoine, P. Tricart, G. Boillot

Ultramafic and gabbroic ocean floor of the Ligurian Tethys (Alps, Corsica, Apennines): in search of a genetic model

Geology, 15(7) (1987), pp. 622-625

E. Loh

Optical vibrations in sheet silicates

Solid State Phys. 6 (1973), pp. 1091-1104

C.F. Macdonald and J. M. Driessen

The Drainage System of the Domestic Quarter in the Palace at Knossos

BSA 83, (1988), p. 248

L.J. Monkman

Some chemical and mineralogical aspects of the acid decomposition of chrysotile

In Proc. Physics and Chemistry of Asbestos Minerals. Second Intern. Conf. Louvain University, Belgium 6 - 9 Sept. (1971)

A. Morgan, A. Holmes

Solubility iof asbestos and man-made mineral fibers in vitro and in vivo: Its significance in lung disease

Environ. Res. 39 (1986), pp. $475-484$ 
A. Morgan, A. Holmes, A.E. Lally

Solubility of chrysotile asbestos and associated trace metals in $\mathbf{N}$ hydrochloric acid at $25 \mathrm{C}$ In Proc. Physics and Chemistry of Asbestos Minerals. Second Intern. Conf. Louvain University, Belgium 6 - 9 Sept. (1971)

P.A. Mountjoy, B. Burke, K. S. Christakis, J. M. Driessen, R.D.G. Evely, C. Knappet, O.H. Krzyszkowska

Knossos. The South House

BSA Suppl. Vol. no. 34. (2003), p. 172

A. Orphanoudaki - Manousaki

Ophiolites of the island of Crete

PhD Thesis, National Technical University of Athens (1987), p. 42

R.G. Rapp

Archaeomineralogy

Springer Science \& Business Media, Berlin (2002), p. 119

B. Reynard, J.D. Bass, J.M. Jackson

Rapid identification of steatite-enstatite polymorphs at various temperatures

Journal of the European Ceramic Society 28 (2008) pp. 2459-2462

C. Rinaudo, D. Gastaldi, E. Belluso

Characterization of chrysotile, antigorite and lizardite by FT-Raman spectroscopy

The Canadian Mineralogist, Vol. 41 (2003), pp. 883-890

R. J. Rodden

Excavations at the Early Neolithic Site at N. Nikomedeia

PPS NS 28 (1962), p. 267-288.

G.J. Rosasco and J.J. Blaha

Raman microprobe spectra and vibrational mode assignments of talc

Appl. Spectrosc. 34 (1980), pp. 140-144

H. Schreier, J. Omueti, L. Lavkulich

Weathering Processes of Asbestos-rich Serpentinitic Sediments

Journal of the soil science society America, Vol. 51 No. 4 (1987), pp. 993-999

J.W. Shaw

Minoan Architecture: Materials and Techniques

Bottega d'Erasmo, Padova (2009), pp. 26-8, 80-1

S. Spiel, J.P. leineweber

Asbestos minerals in modern technology

Environ. Res. 2 (1969), pp. $166-212$

A. Surour, E. Arafa 
Ophicarbonates: calichified serpentinites from Gebel Mohagara, Wadi Ghadir area, Eastern Desert, Egypt

Journal of African Earth Sciences, Vol. 24 (3) (1997), pp. 315-324

G. Thorbecke

Die gesteine der Ophiolith-Decke von Anoja/Mittelkreta

Ber. Naturf. Ges. Freiburg. i. Br., 63 (1972), pp.81-92

V. Trommsdorff, B. Evans, H. Pfeifer

Ophicarbonate rocks: metamorphic reactions and possible origin

Archive Science, Geneve 33 (1980), pp. 361-364

A. Wang, J. Freeman, K. E. Kuebler

Raman Spectroscopic Characterization of Phyllosilicates

Lunar and Planetary Science XXXIII (2002).

P. Warren

A Stone Vase-Maker's Workshop in the Palace at Knossos

BSA, 62 (1967), pp. 195-201

P. Warren

Minoan Stone Vases

Cambridge London (1969), pp. 140-145

P. Warren

Two stone vases from Knossos

BSA 60 (1965), pp. 248-315.

E. Whittaker, J. Zussman

The characterization of serpentine minerals by $\mathrm{X}$-ray diffraction

Mineralogical Magazine, 31 (1956), pp. 107-126

F. Wicks, E. Whittaker

A reappraisal of the structures of the serpentine minerals

Canadian Mineralogist Vol. 13 (1975), pp. 227-243 